\title{
Dangerous and severe personality disorder:
}

\section{antecedents and origins}

\author{
ANTHONY MADEN
}

\begin{abstract}
Summary The origins of the
Dangerous and Severe Pesonality

Disorder (DSPD) Programme can be

traced to developments in structured

assessment and services for the

cognitive-behavioural treatment of

sexual and violent offenders in other

countries. A comparison with these other services highlights the strengths and

weaknesses of DSPD. The decision to use a

medical model raises ethical and financial

questions that may jeopardise the

Programme's future.
\end{abstract}

\section{Declaration of interest None.}

Politicians and civil servants invented dangerous and severe personality disorder (DSPD) in 1999. The announcement of a new service coincided with the conviction of a notorious offender, Michael Stone, but it is a mistake to attribute too much significance to this piece of political theatre. The true motivation was not a single case but longstanding frustration within government at the refusal of psychiatrists to address the problem of high-risk offenders with personality disorder. The profession was seen as cynically hiding behind the 'treatability' clause in the Mental Health Act 1983 in order to avoid responsibility for dangerous and difficult patients.

The DSPD diagnosis and service appeared suddenly but not from nowhere. Too much has been made of the claim that all is new and we know nothing, the attraction of the tabula rasa being that any old scribble can pass for wisdom. Certainty may be hard to come by but an educated estimate of the strengths and weaknesses of the DSPD Programme emerges readily from a study of its antecedents which include: (a) decreasing tolerance for the risks associated with crime and violence; (b) standardised risk assessment and the Psychopathy Checklist; (c) cognitive-behavioural programmes for sexual and violent offenders; (d) the Dutch TBS system; (e) the Violence Reduction Programme in Saskatoon, Canada.

\section{DECREASING TOLERANCE FOR RISKS ASSOCIATED WITH CRIME AND VIOLENCE}

Blaming the government is the UK's fastest growing indoor sport, but decreasing tolerance of violence risk is a global phenomenon that extends far beyond mental health. We assumed that the violent, like the poor, would always be with us, until California and New York City, along with other parts of the USA, broke with this consensus in the 1990s and achieved significant reductions in crime rates. The costs were high as the prison population soared, but voters saw it as a bargain and other countries have adopted similar policies. Most changes in the UK have been to criminal sentencing. Although mental health has not been singled out for special treatment it could not expect to remain untouched by such sweeping social changes. The pressure on mental health services comes from new expectations rather than new law, and the only legal change is likely to be loss of the 'treatability' clause in the Mental Health Act.

\section{STANDARDISED RISK ASSESSMENT AND THE PSYCHOPATHY CHECKLIST}

Without the Psychopathy Checklist - Revised (PCL-R; Hare, 1991) there could have been no DSPD service. The diagnosis of psychopathy has a long history but had fallen into disuse for want of a reliable diagnostic method. Much of the problem lay with the DSM diagnosis of antisocial personality disorder which was hopelessly confounded with criminality (American Psychiatric Association, 1994). Hare resurrected the concept of psychopathy by developing a simple yet reliable and valid method for diagnosis.

Although the DSPD Programme embraced the concept of psychopathy it did not heed the advice of most practitioners about the implications for treatment. High psychopathy scores suggest poor response to all aspects of treatment. The evidence base, scanty though it is, favours treatment of people with a range of scores rather than an attempt to treat large numbers of people with high psychopathy scores together. The decision to go against this evidence is probably the greatest strategic risk taken by the programme.

The development of the PCL-R coincided with massive growth in the risk assessment industry. It began as a welcome improvement on unstructured clinical assessment, but was damaged by overenthusiastic claims that actuarial methods should replace inferior clinical approaches. The debate has settled to a consensus view that structured clinical judgment is the best way of assessing violence risk in an individual. Structured methods should inform the clinical judgement but cannot replace it (Monahan, 1992).

The DSPD service is ahead of most UK forensic services in its use of standardised measures of personality disorder and risk. One of the strongest aspects of the service is its use of dynamic measures to assess the progress of treatment, which is less contentious than the use of risk measures in sentencing. On the negative side, planners and civil servants expect too much from actuarial measures and worry when a man with 'the right scores' is not considered suitable for admission, or vice versa. Further education is needed and Mullen (2007) has made a good start.

Fortunately when it comes to detention in hospital, science and the law are on the same side. Human rights legislation ensures that doctors have the final say in deciding on 'unsound mind' - which provides reassurance against the spectre of politicians using mental health services as a means of social control, but raises a more difficult series of questions for the profession. How do doctors define treatment needs in personality disorder? Which treatments do doctors believe are suitable for which types of patient? When and how do doctors judge that coercive treatment is likely to be effective? The Mental Health Act 1983 allowed doctors to opt out of involvement with patients with psychopathy, so many 
doctors are considering these issues for the first time. There is no consensus within the profession. Some experienced psychiatrists recommend treatment of patients with DSPD whereas other experienced psychiatrists advise tribunals that these same patients are untreatable. Standardisation still has some way to go in this field.

\section{COGNITIVE-BEHAVIOURAL PROGRAMMES FOR SEXUAL AND VIOLENT OFFENDERS}

The criminal justice system of the 1980s laboured under the pessimistic belief that nothing could be done about the tendency of offenders to carry on reoffending until they grew out of it or died. This approach was not helpful for prisoners or prison staff. In the 1990s the pendulum swung the other way. The search for 'What Works' was a corrective to the nihilism that had gone before - and the answer to that question appeared to be cognitivebehavioural programmes.

Offending behaviour programmes have swept through the criminal justice systems of several countries, including the UK (see McGuire, 1995). The prison system is ahead of the National Health Service, where forensic services emphasised medical treatment of the underlying disorder and were slower to take up cognitive-behavioural therapy (CBT). Some hospital practitioners even argued that the prevention of reoffending should not be a primary goal of forensic mental health services, although this argument appears to have been resolved in favour of the common sense view that even the best mental health treatment serves little purpose if it is rapidly followed by reoffending and a return to custody. Most forensic services are now adopting cognitive-behavioural programmes similar to those found in many prisons.

If the criterion is number of customers then cognitive-behavioural/offending behaviour programmes are a smash hit that will run and run. However, the scientific evidence falls short of a rave review and there is no adequate evidence from randomised controlled studies. The following examples refer to the treatment of sex offenders but there is no reason to hope for better results in violent offenders. Moreover, as violence has always been more socially acceptable than sexual offending, treatment of violent offenders will probably be more difficult.
Hanson et al (2002) reviewed 43 studies that included at least a matched, untreated group, yielding a total of 9454 sexual offenders (5078 treated and 4376 untreated). Meta-analysis showed a significant reduction in recidivism rates in the treated group: treated $v$. untreated recidivism rates were $12.3 v .16 .8 \%$ for sexual offending and $27.9 v .39 .2 \%$ for all offending. If the analysis includes only treatments meeting current standards for offending behaviour programmes the results are better: $9.9 v .17 .4 \%$ for sexual recidivism and $32 v .51 \%$ for all offending.

The existence of an apparently effective treatment for the management of sexual offenders has led to optimism, but we need to keep it within proper bounds. Marshall \& McGuire (2003) emphasise that we do not know 'with which types of offenders' treatment is most likely to be effective (p. 654). We can assume that outcome will be best in those whose offending was confined to a domestic setting, in the absence of personality disorder or an otherwise deviant lifestyle. Treatment is most likely to succeed in those who have most to lose in terms of employment, self-image and social standing. It is likely to be most difficult in predatory offenders, and in those with 'stranger' victims and high psychopathy scores - in other words, those for whom DSPD services were designed.

Brooks-Gordon \& Bilby (2006) highlight the 'enormous political and institutional pressure to prove that treatment works' but note the methodological limitations of the evidence to date as well as the rather poor results revealed by the Cochrane meta-analysis (Kenworthy et al, 2004). Cognitive-behavioural therapy may be the best hope for success in DSPD treatment but further results are awaited.

Overenthusiastic advocates of 'What Works' should also bear in mind that although CBT has a growing reputation as the wonder treatment for all psychological problems more evidence of its efficacy is required. A good example of this need for caution would be its use in the treatment of schizophrenia. A review of 20 randomised controlled trials indicated modest effect sizes, with the strongest evidence available for chronic patients (Tarrier $\&$ Wykes, 2004). It may be too early to say, but nobody should be surprised if similar conclusions emerge in relation to CBT in the population with DSPD.

If this all sounds very negative, it is important to remember the positive aspects of CBT. Its structured approach and comprehensibility make it suitable for a difficult client group. Its explicit procedures and aims facilitate evaluation. At present it is probably still the best available treatment but it has much to prove.

\section{THE DUTCH TBS SYSTEM}

An important stimulus for the development of the DSPD Programme in the UK was the feeling that the Dutch, just across the North Sea, were doing things so much better. The TBS system has been managing high-risk violent and sexual offenders in institutions and in the community since 1928 and nobody could disagree with the suggestion that we have a lot to learn from them. The big question is precisely what we should learn. The danger is that we use their approach as a giant Rorschach ink blot in which we see only what suits us but ignore the obvious and inconvenient.

Under TBS legislation, offenders convicted of a serious sexual or violent offence and judged to present a high risk of reoffending can be sentenced by the criminal court to a TBS order. They serve a prison sentence appropriate to the offence and are transferred to a TBS facility for treatment at the end of that sentence. They remain within the TBS system indefinitely (subject to regular review by a tribunal), first in a secure institution and later as conditionally discharged, supervised patients in the community. Dutch courts rarely give a sentence of life imprisonment and the TBS order is in many ways a substitute.

Treatment within the TBS system is eclectic, with a strong emphasis on therapeutic community principles and on work: patients are expected to spend about half the week in paid employment. In recent years the service has embraced the PCL-R and other standardised measures, as well as CBT offending behaviour programmes. Antilibidinal medication is commonly prescribed to sex offenders and accounts for a considerable proportion of medical input, as most other treatments are delivered by psychologists or specially trained (nonmedical) therapists. There is a well-developed community service and most patients progress rapidly to supervised leave from the in-patient units.

The civil servants who created the DSPD Programme were obviously impressed by the TBS system so it is remarkable how little of it they chose to adopt. No new legislation was introduced so the 
criminal courts play no role in sending offenders to DSPD units. Paid work remains deeply unfashionable within most English psychiatric hospitals, and in the notoriously fashion-resistant high-secure estate its availability is severely restricted by security considerations. The DSPD Programme developed as a high-security in-patient service with no clear pathway to the community.

The most important difference may be that the DSPD Programme lacks the legitimacy that the Dutch courts give to TBS. English and Welsh life-sentenced prisoners are in a similar position to Dutch TBS patients, but prisoners with determinate sentences feel aggrieved to be transferred to hospital during their sentence then detained beyond its end. The grievance has some justification. The (historical) information to support detention on the grounds of risk was available at the time of sentencing, so it is reasonable to ask why indeterminate detention is appropriate now if it was not considered appropriate by the sentencing judge.

A further problem arises from the Mental Health Act 1983 which requires that treatment be likely to 'ameliorate or prevent deterioration' if a patient is to be detained on the grounds of psychopathic disorder. This unfortunate wording has led many patients to seek discharge on the grounds that they are untreatable, a quest in which they are often supported by their legal representatives and some doctors who testify to tribunals. In practice, tribunals do not discharge many high-risk patients, but much time and money is wasted along the way. It may be many years before the realisation dawns that the tribunal route is not the best way out of hospital, and tremendous damage can be done to the service if those years are spent by the patient in a determined effort to prove intractability. By contrast, the TBS system delivers a clear message that the only way out is by demonstrating reduced risk, hence sustained non-adherence to treatment is rare. The viability of DSPD services may depend on a change in UK law that brings similar clarity.

Another major difference is that TBS units are not dominated by doctors and nurses. Conventional medical attitudes are inappropriate for people without a mental illness. English high-security hospitals have tended to infantilise patients and remove all responsibility from them. Such an approach is unhelpful to any patient, but it is

ANTHONY MADEN, FRCPsych, Imperial College, Department of Forensic Psychiatry, Academic Centre, West London Mental Health NHS Trust, Southall, Middlesex UBI 3EU, UK. Email: a.maden@ic.ac.uk

disastrous in a personality disorder service whose primary aim is to encourage patients to accept responsibility for their own behaviour.

The TBS units can also teach us about long-stay patients. About $20 \%$ of their patients are judged unlikely ever to be discharged after an initial treatment period of about 6 years. The assumption is that they will be detained indefinitely in units that give priority to quality of life. As the DSPD Programme has higher threshold criteria than the TBS system, it is likely that a much higher proportion of DSPD patients will never be considered suitable for discharge. Unless plans are made for them they will become a source of dissatisfaction and instability within the service.

\section{THE VIOLENCE REDUCTION PROGRAMME IN SASK ATOON, CANADA}

The Violence Reduction Programme operates within a regional psychiatric centre in Saskatoon, a specialised unit of the Canadian correctional System, and it has been contrasted with the DSPD Programme (Maden et al, 2004). It is important as a model of a service based on cognitivebehavioural principles and using standardised measures of change.

There are two major differences from the DSPD Programme. First, the unit is part of the prison system, so all patients are serving prisoners who have volunteered for the service and can be sent back to ordinary prisons if they are violent within the unit or if treatment is not progressing. Second, the Canadian correctional system includes a 'Supermax' prison that effectively provides back-up for dealing with the most disruptive or violent prisoners who are not suitable for the regional psychiatric centre. Such a facility exists within the UK prison system and can provide support for prison DSPD units, but there is no equivalent resource within the high-security hospitals. The techniques required to deal with violent and disruptive prisoners inevitably involve restraint and are quite different from the techniques used within the regional psychiatric centre in Saskatoon, where any violent act results in transfer out. The Canadian system manages these types of offender separately because they have different needs. The DSPD Programme may run into problems because it has committed itself to managing them together in the hospital units. The skills, techniques and building needed for the two groups are very different. Hence the DSPD Programme is effectively committed to providing two parallel services when one would provide more than enough of a challenge.

\section{THE FUTURE}

Missing from the list above are those services that had little influence on the development of the DSPD Programme and deserved consideration. Chief among these is the discretionary lifer system in the UK, consisting of offenders who were given a life sentence not because of their offence alone but because of their perceived risk. Most had psychopathy, and the system has a good record of safe management and rehabilitation through the criminal justice system, with little medical input. There was scope to increase that input without radical change to the system. Anecdotal evidence suggests that many men within this system with personality disorders spent several years fighting the system before settling in to an active programme of rehabilitation. The challenge for DSPD services is to show that they can do better with similar men, and they face a major handicap from the stigma attached to the label.

Comparison with other services shows that the architects of the DSPD service took some major strategic risks when they decided to go down a different road. They took those risks in a high-stakes game, and the most important risk may turn out to be financial. The cost of DSPD treatment in high-security hospitals is over $£ 200000$ per patient per year, a sum that can buy a lot of risk management in other settings. People who work in DSPD programmes already feel their practice is subject to close examination, but it may be nothing compared with the scrutiny heading their way from the accountants.

\section{REFERENCES}

American Psychiatric Association (1994) Diagnostic and Statistical Manual of Mental Disorders (4th edn) (DSM-IV). APA 
Brooks-Gordon, B. \& Bilby, C. (2006) Psychological interventions for treatment of adult sex offenders. BM 333, 5-6.

Hanson, R. K., Gordon, A., Harris, A. J. R., et al (2002) First report of the collaborative outcome data project on the effectiveness of psychological treatment for sex offenders. Sexual Abuse: A Journal for Research and Treatment, 14, 167-192.

Hare, R. D. (199I) The Hare Psychopathy Checklist Revised. Multi-Health Systems.

Kenworthy, T., Adams, C., Bilby, C., et al (2004)

Psychological interventions for those who have sexually offended or are at risk of offending. Cochrane Database of Systematic Reviews, Issue 3. Update software.

Maden, A., Williams, J., Wong, S. C. P., et al (2004) A service for dangerous severe personality disorder in high security hospital: lessons from the Canadian Regional Psychiatric Centre. Journal of Forensic Psychiatry and Psychology, I5, 375-390.

Marshall, W. L. \& McGuire, J. (2003) Effect sizes in the treatment of sexual offenders. International journal of Offender Therapy and Comparative Criminology, 47, 653-663.
McGuire, J. (1995) What Works: Reducing Reoffending. Wiley.

Monahan, J. (1992) Mental disorder and violent behaviour: perceptions and evidence. American Psychologist, April 1992, 51I-521.

Mullen, P. E. (2007) Dangerous - and severe

personality disorder - and in need of treatment. British Journal of Psychiatry, 190 (suppl. 49), s3-s7.

Tarrier, N. \& Wykes, T. (2004) Is there evidence that cognitive behavioural therapy is an effective treatment for schizophrenia? A cautious or cautionary tale? Behaviour Research and Therapy, 42, 1377-1401. 